\title{
Antimicrobial Activity of Silver Nanoparticles Synthesized with Extract of Tomato plant Against Bacterial and Fungal Pathogens
}

\author{
Mehmet Firat Baran ${ }^{1}$, Hilal Acay ${ }^{2}$ \\ ${ }^{1}$ Mardin Artuklu University, Medical Laboratory Techniques, Vocational Higher School of Healthcare Studies, 47200 Mardin, \\ Turkey. \\ ${ }^{2}$ Department of Nutritition and Dietetic, Faculty of Health Science, Mardin Artuklu University, Mardin, Turkey
}

Received: 09 April 2019, Accepted 29 June 2019, Published online: 28 August 2019

(C) Ordu University Institute of Health Sciences, Turkey, 2019

\begin{abstract}
Objective: Silver nanoparticles (AgNPs) have a wide range of applications. Environmental-friendly synthesis methods for these nanoparticles are more preferable due to their various advantages. This study aimed to synthesize AgNPs using the extract of the tomato plant in an easy and economical way. and testing this AgNPs against some human pathogens.

Methods: Silver nanoparticles were synthesized using aqueous silver nitrate and reducing tomato plant extract. The characterization of AgNPs was determined by ultraviolet-visible spectrophotometry (UV-Vis), X-ray crystallography (XRD) Scanning electron microscopy (SEM), Fourier transform infrared Spectroscopy (FT-IR), energy dispersive X-ray spectrum (EDAX), thermogravimetric - differential thermal analysis (TGA-DTA) data. The effects of the particles on pathogenic microorganisms were determined by minimum inhibition concentration (MIC).

Results: These data, with a maximum absorbance of $450.51 \mathrm{~nm}$, in the spherical view, with the peaks and values of $111^{\circ}, 200^{\circ}, 220^{\circ}$ and $311^{\circ}(38.08,44.28,64.42$ and 77.34), AgNPs showed a cubic crystal structure and, using the Debye-Scherrer equation, it was determined that they had a crystal size of $21.11 \mathrm{~nm}$ AgNPs had an antimicrobial activity on hospital pathogens gram negative, gram positive and Candida albicans yeast. Conclusion: We found that these particles showed antimicrobial activity on various microorganisms even at very high concentrations. As a solution to the antimicrobial search, it can be developed in medical industry. Key words: Antimicrobial activity, XRD, SEM, TGA-DTA, Silver nanoparticle
\end{abstract}

Suggested Citation: Baran MF, Acay H. Antimicrobial Activity of Silver Nanoparticles Synthesized with Extract of Tomato plant Against Bacterial and Fungal Pathogens. Middle Black Sea Journal of Health Science, 2019; 5(2): 67-73

Address for correspondence/reprints:

Hilal Acay

Telephone number: +90 (482) 2121395

E-mail: hilalacay@gmail.com

DOI: $10.19127 / \mathrm{mbsjohs.551132}$

\section{Introduction}

Nanoparticles (NPs) are structures smaller than $100 \mathrm{~nm}$. Nanotechnology is a branch of technology that examines the properties of these structures (Beyene et al., 2017). The increasing use of NPs makes these structures more important every day (Tovar-Corona et al., 2018). NPs such as gold, silver, platinum, copper, palladium etc. are widely used in a wide range of areas including personal care, clothing, cosmetics, food industry, catalysis and medical, optic and electronic industries (Lloyd et al., 1998; Song et al., 2010; Gopinath et al., 2016; 
Vetchinkina et al., 2016; Prakash et al., 2018). Silver nanoparticles (AgNPs) have large surface areas and a high conductivity capacity and they can be synthesized using various biological sources (Nanda et al., 2018). In addition, AgNPs can be synthesized both physically and chemically, however this may have various disadvantages compared to biological methods.Chemical methods lead to the presence of some toxic chemicals adsorbed on the surface that may have adverse effects in medical applications (Jain et al., 2009; Baran, 2019). Phytochemicals in plant reduce Ag+ to $\mathrm{AgO}$ structure and provide the stabilityof AgNPs. (Ali et al., 2015; Saha et al., 2017). The use of colloidal silver for the treatment of diseases has been the subject of research for more than 50 years. Recent developments in the chemical, biological and material characterization techniques have allowed this subject to be explored better and silver has begun to be used more widely in the medical fields (Brandt et al., 2012). These particles have a strong antimicrobial activity thus, approximately 320 tons of AgNPs are produced every year (Gliga et al., 2014).

In the present study, an AgNP was synthesized in an easy way using the extract of the tomato plant during the autumn period and an inexpensive, simple and environmentally friendly method and the effects of this particle on various microorganisms were examined.

\section{Methods}

\section{Preparation of the Tomato Plant Extract and Silver Nitrate Solution}

The tomato plants used in this study were collected in the agricultural region of Yenişehir in the district of Diyarbakır, Turkey when they were still unripe during the autumn period They were washed several times with tap water and then distilled water and were left to dry at room temperature. $50 \mathrm{gr}$ of the plant was mixed with 500 $\mathrm{ml}$ distilled water and boiled. After being filtered for several times, it was kept at $+4^{\circ} \mathrm{C}$ for synthesis. 1 $\mathrm{mm}$ aqueous solution was prepared with silver nitrate (AgNO3) of $99.8 \%$ purity was purchased from Alfa Aesar."

\section{Synthesis and Characterization}

The extract and the AgNO3 solution were mixed with a ratio of 1:4. The color change of the solution was monitored based on time. The formation and presence of AgNPs were observed using Perkin
Elmer UV- Vis spectrophotometer. The FTIR analysis and functional groups responsible for the reduction in the synthesis were examined with Perkin Elmer Spectrum One. After the synthesis, AgNPs were centrifuged at $10.000 \mathrm{rpm}$ for $15 \mathrm{~min}$ with OHAUS FC 5706 model device. The bottom precipitate was washed with distilled water and dried at $75^{\circ} \mathrm{C}$. The evaluation of content of the particles was carried out with Bruker-125 eV (EDX). ). The formation of AgNPs was examined with scanning electron microscope (SEM) EVO 40 LEQ data. The crystal structures were examined by RadB-DMAX II computer-controlled X-ray diffractometer (XRD) analysis and the crystal particle size was determined using the DebyeScherrer equation and TGA-DTA decay temperature values were checked with Shimadzu TGA-50 device data.

Determination of the Antimicrobial Effects of AgNPs

The effects of AgNPs on pathogenic microorganisms were examined by using the micro dilution method to determine the minimum inhibition concentration (MIC). The effects of the particles were investigated on gram negative Escherichia coli ATCC 25922, Pseudomonas aeruginosa ATCC 27853 and gram positive Staphylococcus aureus ATCC 29213, Streptococcus pyogenes ATTC 19615 strains and Candida albicans ATTC 10231 strains For the bacteria in the microplate wells, Mueller Hinton broth and for the fungus RPMI broth were added. The solutions prepared from AgNPs were placed on plates at the appropriate concentrations and a mixture of microorganisms was added according to MC Farland standard 0.5 concentration (Nishanthi et al., 2019) and waited for one night at $37 \mathrm{oC}$. The MIC values of Vancomycin for gram positives, colistin and flucanozol antibiotics for gram negatives and fungi, and the aqueous solution of 1 $\mathrm{mM}$ AgNO3 were also investigated.

\section{Results}

After taking $500 \mathrm{ml}$ from the $1 \mathrm{mM} \mathrm{AgNO}_{3}$ solution and $100 \mathrm{ml}$ from the plant extract and mixing $1000 \mathrm{ml}$ in conical flask, a dark brown discoloration was observed after $75 \mathrm{~min}$. The absorbance data of UV-Visible measurement results are given in Figure 1. The dark brown discoloration is a characteristic data showing the formation of AgNPs due to vibrations on the plasma surface and 
the maximum peak value at $450.51 \mathrm{~nm}$ and the absorption data also support this fact (Figure 1).

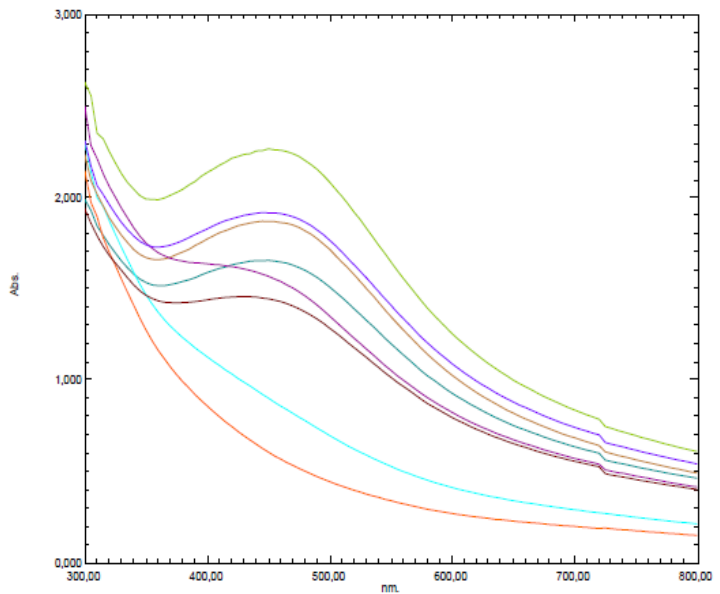

Figure 1A. Time Dependent of AgNPs in UV Visible Spectroscopy

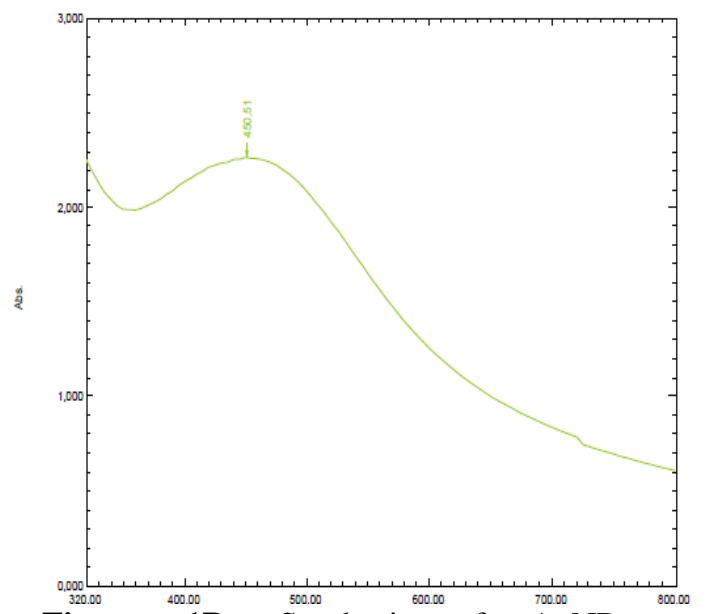

Figure 1B. Synthesis of AgNP ${ }^{5000000}{ }^{500000}$ at UV Spectrophotometry Maximum Absorbance Value

In this study, when the functional groups participating in the reduction were examined, it was determined that the shifts at 3511, 3206, 2148 and $1618 \mathrm{~cm}-1$ corresponded to $-\mathrm{OH},-\mathrm{NH},-\mathrm{CN}$ and $\mathrm{C}=\mathrm{O}$ respectively (Figure 2 .)

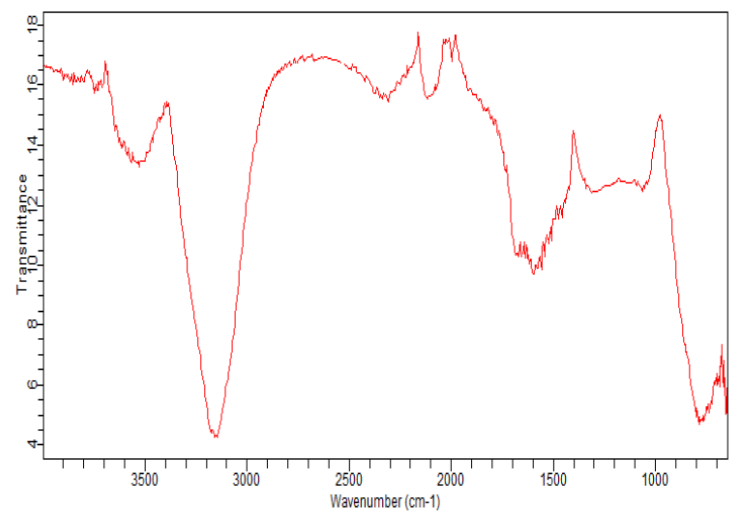

Figure 2A. FT-IR spectrum of extract spectrum.

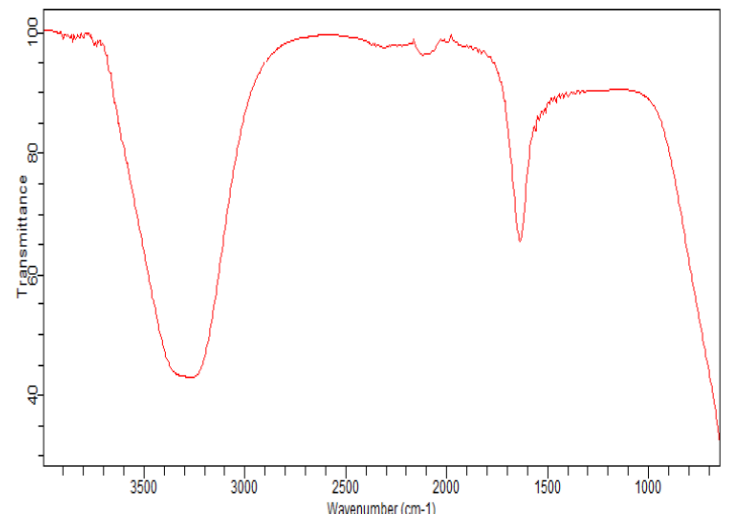

Figure 2B. FT-IR spectrum of synthesised AgNPs.

In the XRD analysis data, the peaks of $111^{\circ}$, $200^{\circ}, 220^{\circ}$ and $311^{\circ}$ are the peaks that correspond to the peaks at $2 \theta$ which represent the cubic crystal structure of silver (Figure 3). The crystal size of AgNPs was calculated by the Debye-Scherrer equation given below and was found to be 22.11 nm. $\mathrm{D}=\mathrm{K} \lambda /(\beta \cos \theta)$

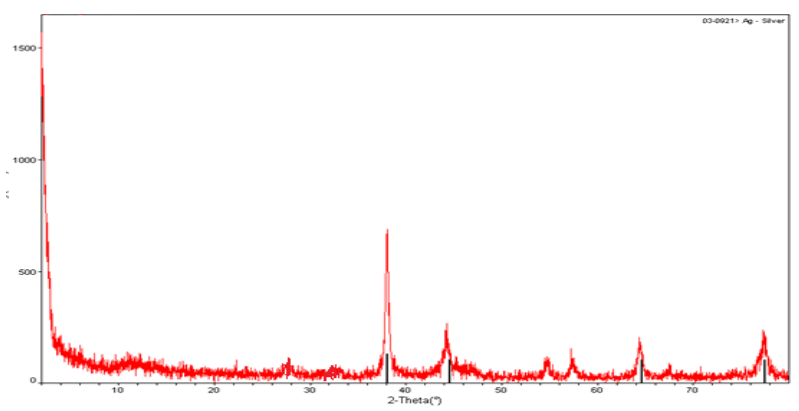

Figure 3. Investigation of crystal structure and silver phases of AgNPs by XRD analysis

The SEM results for examining the morphological views of AgNPs give us that NPs are in spherical view and have an average $52.74 \mathrm{~nm}$ of dimensions (Figure 4).

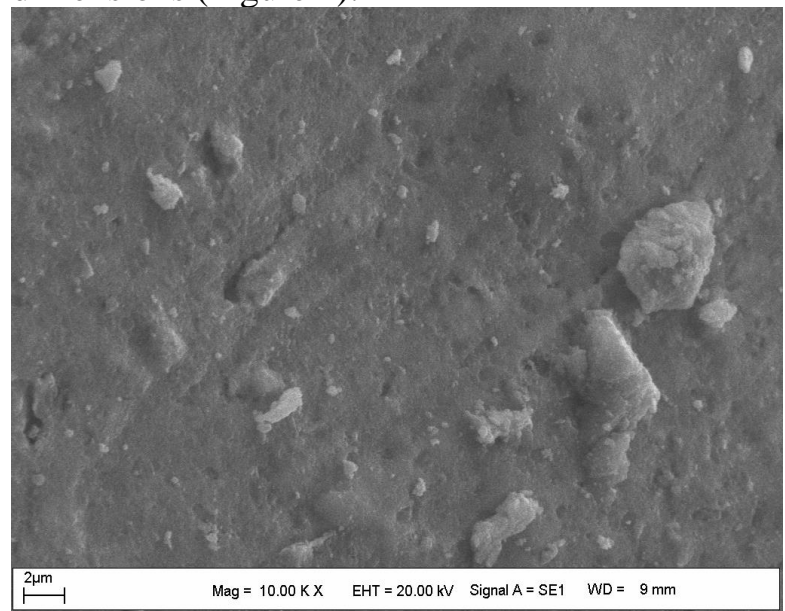


Figure 4A. Evaluation of morphology of AgNPs in SEM results A) 10,000 times magnified view of AgNPs

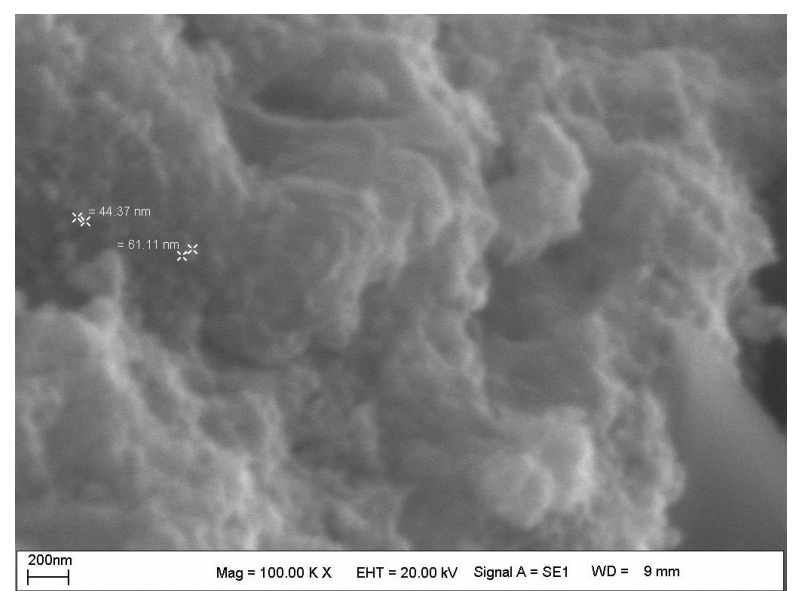

Figure 4B. Evaluation of morphology of AgNPs in SEM results 100,000 times magnified view of AgNPs

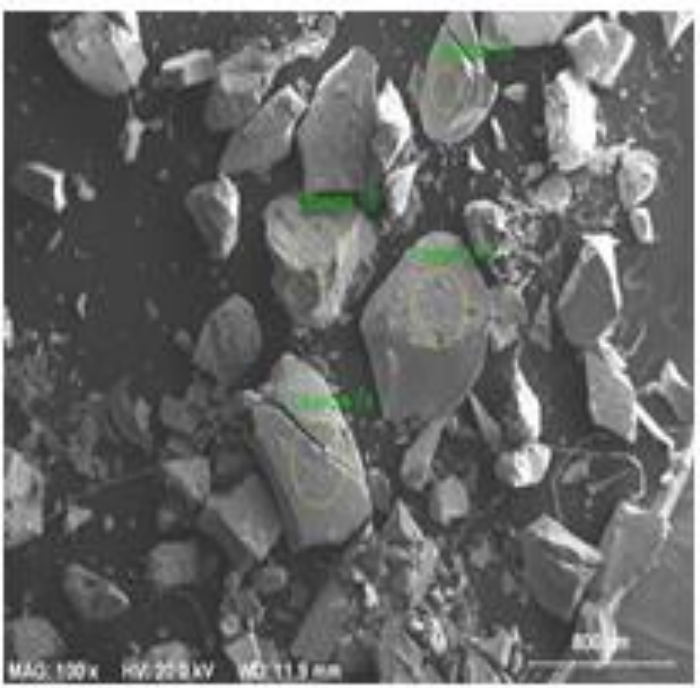

Figure 5 A. Analysis of the elemental composition by the EDX analysis of AgNPs. EDX measurement with three different points,

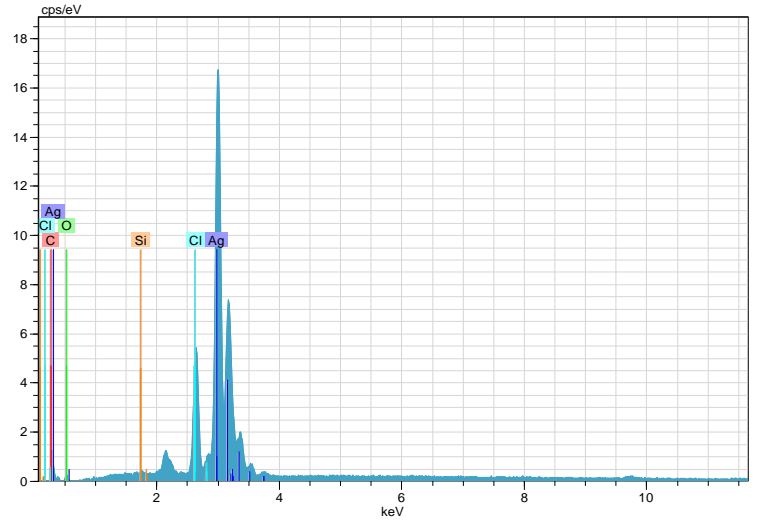

Figure 5B. Analysis of the elemental composition by the EDX analysis of AgNPs. EDX pattern showing the presence of silver
When the element content was examined according to the results of EDX (figure 5), it was found that it was mostly composed of silver the TGA-DTA curve was examined, it was thought that the mass loss of $2.24 \%$ at $12-227^{\circ} \mathrm{C}$ was due to the hydration by moisture and water, the mass loss of $3.8 \%$ at $227-355^{\circ} \mathrm{C}$ was due to phytochemicals present in the plant extract, and the mass loss of $23 \%$ at $355-846^{\circ} \mathrm{C}$ was due to the structure of the substance deteriorating (Figure 6). AgNPs showed a suppressive effect against microorganisms. When the AgNPs obtained in this study were compared with the antibiotic and $5 \mathrm{mM} \mathrm{AgNO} 3$ solution, the effect of Ag NPs was examined in low concentrations (Table 1).

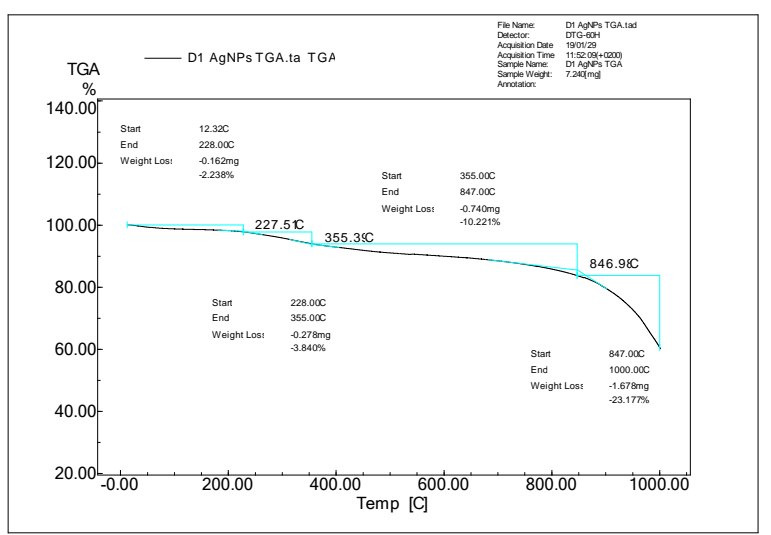

Figure 6A. TGA-DTA data of the synthesized nanoparticle. Nanoparticle TGA curve at different temperatures

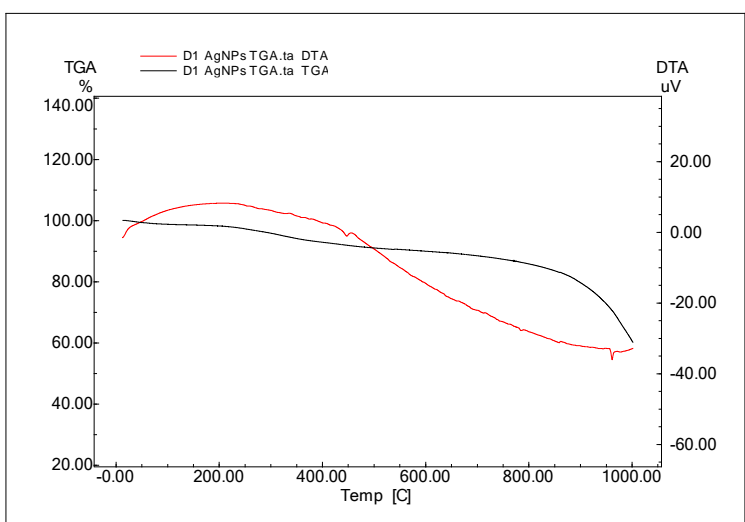

Figure 6B. TGA-DTA data of the synthesized nanoparticle. Nanoparticle DTA curve at different temperatures 
Table 1. MIC values of Synthesized silver nanoparticles (AgNP) $\left(\mathrm{mg} \mathrm{mL}^{-1}\right)$ on Silver nitrate solution and vancomycin, fluconazole, colistin antibiotics, S. Aureus, S.pyogenes, S. albicans and E. Coli, P.aeruginosa microorganisms.

\begin{tabular}{|c|c|c|c|c|}
\hline & ORGANISM & AgNPs & $\begin{array}{l}\text { Silver } \\
\text { Nitrat }\end{array}$ & Antibiotic \\
\hline \multirow{2}{*}{ 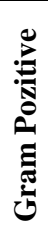 } & $\begin{array}{l}\text { S. aureus } \\
\text { ATCC } 29213\end{array}$ & 0.035 & 2.65 & 1 \\
\hline & $\begin{array}{l}\text { S.pyogenes } \\
\text { ATTC } 19615\end{array}$ & 0.035 & 1.32 & 1 \\
\hline \multirow{2}{*}{ 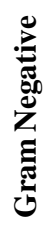 } & $\begin{array}{l}\text { E. coli } \\
\text { ATCC25922 }\end{array}$ & 0.017 & 0.66 & 2 \\
\hline & $\begin{array}{c}\text { P.aeruginosa } \\
\text { ATCC } 27853\end{array}$ & 0.009 & 0.66 & 2 \\
\hline 焉 & C. albicans & 0.018 & 0.66 & 2 \\
\hline
\end{tabular}

\section{Discussion}

The presence of AgNPs was determined by detecting dark brown color changes by UV-Vis. The maximum absorbance values at the $345 \mathrm{~nm}$ wavelength in the results are the data showing the character of AgNPs. The dark brown color changes are a characteristic data showing the formation of AgNPs due to vibrations on the plasma surface (Begum et al., 2009; Prakashet al., 2013; Sinsinwar et al., 2018). Similar values found as a result of other studies conducted regarding the synthesis of AgNPs using plants are also in correlation with the results of the present study (Ferreyra et al., 2018; Shao et al., 2018). The XRD results show us the peaks: $111^{\circ}, 200^{\circ}, 220^{\circ}, 311^{\circ}$ and $38.08,44.28$, 64.42 and 77.34. The values of these peaks indicate the characteristic of AgNPs. The results of different studies in literature interpreted these peaks as AgNPs (Sengottaiyan et al. 2016; Khan et al., 2018). In accordance with this data, the crystal size of AgNPs was calculated $22.11 \mathrm{~nm}$. In similar studies, NPs were evaluated using Debye-Scherrer equation (Sagar and Ashok, 2012; Pugazhendhi et al., 2018). In this study, when the functional groups participating in the reduction were examined, it was determined that the shifts at 3511, 3206, 2148 and $1618 \mathrm{~cm}^{-1}$ corresponded to $-\mathrm{OH},-\mathrm{NH},-\mathrm{CN}$ and $\mathrm{C}=$ $\mathrm{O}$ respectively. It was observed that the reduction of the tension in $3511 \mathrm{~cm}^{-1}$ did not occur at the end of the reaction, and other functional groups were also involved in the reduction when the FTIR images in Figure 2 were examined. These groups were evaluated in studies for the synthesis of other AgNPs (Baran, 2019). The SEM results showed that AgNPs were global in appearance. Some studies mention that AgNPs are in spherical view and have an average $52.74 \mathrm{~nm}$ of dimensions (Hemmati et al., 2019; Singh et al., 2017). Other studies also state that AgNPs are in global view (Kumar et al., 2016; Kobashigawa et al., 2018). When the TGA-DTA curve was examined, it was thought that the mass loss of $2.24 \%$ at $12-227^{\circ} \mathrm{C}$ was due to the hydration by moisture and water, the mass loss of $3.8 \%$ at 227 $355^{\circ} \mathrm{C}$ was due to phytochemicals present in the plant extract, and the mass loss of $23 \%$ at $355-846^{\circ} \mathrm{C}$ was due to the structure of the substance deteriorating In one study, the results are almost identical (Baran, 2019). Various studies in literature showed that AgNPs had a repressive effect on the reproduction of various microorganisms (Singh et al., 2017; Alsammarraie et al., 2018; Baran, 2019). AgNPs increase the formation of reactive oxygen species (ROS) by disrupting the membrane structure of the microorganisms, and negatively affect the functions of structures such as DNA and proteins, which provide other vital activities (Ahmed et al., 2018 ; Sarkar et al., 2018).

\section{Conclusions}

AgNPs are used in a wide range of areas. Due to their antibiotic resistance properties, these nanomaterials can play a key role in the search for antimicrobial agents. Due to the advantages of environmentally friendly methods, the interest in AgNPs increases every day. In this study, AgNPs were synthesized from the green parts of the tomato plant using simple, inexpensive and environmentally friendly methods. AgNPs were characterized and it was determined that, these particles hada maximum absorbance of $450.51 \mathrm{~nm}$, a spherical size of $52.74 \mathrm{~nm}$, a cubic crystal structure and a crystal size of $21.11 \mathrm{~nm}$

It was determined that AgNPs had an antimicrobial activity on various microorganisms even at very high concentrations. In conclusion, AgNPs can be developed in the medical industry for the antimicrobial search. 
Peer-review: Externally peer-reviewed.

Author Contributions: Concept - MFB, HA Design - MFB, HA Supervision- MFB, HA ; Materials MFB, HA ; Data Collection and/or Processing - MFB, HA ; Analysis and/or Interpretation - MFB, HA Literature Review MFB, HA Writing - MFB, HA ; Critical Review MFB, HA

Conflict of Interest: No conflict of interest was declared by the authors.

Financial Disclosure: The authors declared that this study hasn't received no financial support.

\section{References}

Ahmed B, Hashmi A, Khan MS, Musarrat J. ROS mediated destruction of cell membrane, growth and biofilms of human bacterial pathogens by stable metallic AgNPs functionalized from bell pepper extract and quercetin, Adv Powder Technol, 2018, 29(7): 1601-1616. 03.025

Ali K, Ahmed B, Dwivedi S, Saquib Q, Al-Khedhairy A A, Musarrat J. Microwave accelerated green synthesis of stable silver nanoparticles with Eucalyptus globulus leaf extract and their antibacterial and antibiofilm activity on clinical isolates, PLoS One, 2015,10(7): 1-20

Alsammarraie FK, Wang W, Zhou P, Mustapha A, Lin M. Green synthesis of silver nanoparticles using turmeric extracts and investigation of their antibacterial activities", Colloids Surfaces B Biointerfaces, 2018, 171: 398-405..

Baran MF: Synthesis, Characterization And Investigation Of Antimicrobial Activity Of Silver Nanoparticles From Cydonia Oblonga Leaf, 2019, 17(2): 2583-2592.

Begum N A, Mondal S, Basu S, Laskar R A, Mandal D. Biogenic synthesis of $\mathrm{Au}$ and $\mathrm{Ag}$ nanoparticles using aqueous solutions of Black Tea leaf extracts, Colloids Surfaces B Biointerfaces, 2009, 71 (1): 113-118.

Beyene HD, Werkneh AA, Bezabh H K, AAmbaye T G: Synthesis paradigm and applications of silver nanoparticles (AgNPs), a review, Sustain Mater Technol, 2017, 13, January,; 18-23,

Brandt O, Mildner M, Egger AE, et al. Nanoscalic silver possesses broad-spectrum antimicrobial activities and exhibits fewer toxicological side effects than silver sulfadiazine", Nanomedicine Nanotechnology, Biol Med, 2012, 8(4) :478488. .
Ferreyra Maillard A P V, Dalmasso P R, López de Mishima B A, Hollmann A. Interaction of green silver nanoparticles with model membranes: possible role in the antibacterial activity, Colloids Surfaces B Biointerfaces, 2018, 171: 320-326.

Gliga AR, Skoglund S, Wallinder IO, Fadeel B, Karlsson HL. Size-dependent cytotoxicity of silver nanoparticles in human lung cells: the role of cellular uptake, agglomeration and $\mathrm{Ag}$ release, Part Fibre Toxicol, 2014, 11(1): 11.

Gopinath K, Kumaraguru S, Bhakyaraj K, Mohan S, Venkatesh KS, Esakkirajan M, et al. Green synthesis of silver, gold and silver/gold bimetallic nanoparticles using the Gloriosa superba leaf extract and their antibacterial and antibiofilm activities", Microb Pathog, 2016, (101): 1-11.

Hemmati S, Rashtiani A, Zangeneh MM, Mohammadi P, Zangeneh A, Veisi H. Green synthesis and characterization of silver nanoparticles using Fritillaria flower extract and their antibacterial activity against some human pathogens, Polyhedron, 2019, 158: 8-14,

Jain D , Daima HK. , Kachhwaha S., Kothari SL., Synthesis of plant-mediated silver nanoparticles using papaya fruit extract and evaluation of their antimicrobial activities Digest Journal of Nanomaterials and Biostructures, 2009,( 4): 557-563.

Khan AU, Yuan Q, Khan ZUH, Ahmad A, Khan FU, Tahir K, Shakeel M, Ullah S. An eco-benign synthesis of AgNPs using aqueous extract of Longan fruit peel: Antiproliferative response against human breast cancer cell line MCF-7, antioxidant and photocatalytic deprivation of methylene blue, J Photochem Photobiol B Biol, 2018.

Kobashigawa JM, Robles CA, Martínez Ricci ML, Carmarán CC: Influence of strong bases on the synthesis of silver nanoparticles (AgNPs) using the ligninolytic fungi Trametes trogii, Saudi J Biol Sci, 2018, 4-10.

Kumar V, Gundampati R K, Singh D K, Bano D, Jagannadham M V, Hasan S H. Photoinduced green synthesis of silver nanoparticles with highly effective antibacterial and hydrogen peroxide sensing properties, J Photochem Photobiol B Biol, 2016,(162):374-385.

Lloyd JR, Yong P, Macaskie LE. Enzymatic recovery of elemental palladium by using sulfate-reducing bacteria, Appl Environ Microbiol, 1998, 64 (11): 4607-4609. 
Nanda A, Nayak BK, Krishnamoorthy M. Antimicrobial properties of biogenic silver nanoparticles synthesized from phylloplane fungus, Aspergillus tamarii, Biocatal Agric Biotechnol, 16 August 2018, 225-228.

Nishanthi R. Malathi S. John Paul S. Palani P. Green synthesis and characterization of bioinspired silver, gold and platinum nanoparticles and evaluation of their synergistic antibacterial activity after combining with different classes of antibiotics, Mater Sci Eng C, 2019, 96, 693-707.

Prakash P, Gnanaprakasam P, Emmanuel R, Arokiyaraj S, Saravanan M. Green synthesis of silver nanoparticles from leaf extract of Mimusops elengi, Linn. for enhanced antibacterial activity against multi drug resistant clinical isolates, Colloids Surfaces B Biointerfaces, 2013, 108, 255-259.

Prakash S, Elavarasan N, Venkatesan A, Subashini K, Sowndharya M, Sujatha V. Green synthesis of copper oxide nanoparticles and its effective applications in Biginelli reaction, BTB photodegradation and antibacterial activity, Adv Powder Technol, 2018.

Pugazhendhi S, Palanisamy PK, Jayavel R. Synthesis of highly stable silver nanoparticles through a novel green method using Mirabillis jalapa for antibacterial, nonlinear optical applications, Opt Mater (Amst), 2018, 79, 457463.

Sagar G, Ashok B. Green Synthesis of Silver Nanoparticles Using Aspergillus niger and Its Efficacy Against Human Pathogens, Eur J Exp Biol, 2012, 2 (5): 1654-1658.

Saha J, Begum A, Mukherjee A, Kumar S. A novel green synthesis of silver nanoparticles and their catalytic action in reduction of Methylene Blue dye, Sustain Environ Res, 2017, 27(5): 245-250.

Sarkar MK, Vadivel V, Charan Raja MR, Mahapatra SK. Potential anti-proliferative activity of AgNPs synthesized using $\mathrm{M}$. longifolia in 4T1 cell line through ROS generation and cell membrane damage, J Photochem Photobiol B Biol, 2018.

Sengottaiyan A, Mythili R, Selvankumar T, Aravinthan A, Kamala-Kannan S, Manoharan K, Thiyagarajan P, Govarthanan M, Jong-Hoon Kim. Green synthesis of silver nanoparticles using Solanum indicum L. and their antibacterial, splenocyte cytotoxic potentials, Res Chem Intermed, 2016, 42 (4): 3095-3103.
Shao Y, Wu C, Wu T, Yuan C, Chen S, Ding T, Ye $\mathrm{X}, \mathrm{Hu} \mathrm{Y}$. Green synthesis of sodium alginatesilver nanoparticles and their antibacterial activity, Int J Biol Macromol, 2018.

Singh A, Sharma B, Deswal R. Green silver nanoparticles from novel Brassicaceae cultivars with enhanced antimicrobial potential than earlier reported Brassicaceae members, J Trace Elem Med Biol, 2018, 47, , 1-11.

Sinsinwar S, Sarkar MK, Suriya KR, Nithyanand P, Vadivel V. Use of agricultural waste (coconut shell) for the synthesis of silver nanoparticles and evaluation of their antibacterial activity against selected human pathogens, Microb Pathog, 2018, 124,30-37

Song JY, Kwon EY, Kim BS. Biological synthesis of platinum nanoparticles using Diopyros kaki leaf extract, Bioprocess Biosyst Eng, 2010, 33(1):159-164.

Tovar-Corona A, Lobo-Sánchez MA, HerreraPerez J L, Zanella R, Rodriguez-Mora J I, Vázquez-Cuchillo O. Green synthesis of copper (0) nanoparticles with cyanidine-O-3-glucoside and its strong antimicrobial activity, Mater Lett, 2018, 211, 266-269.

Vetchinkina EP, Loshchinina EA, Vodolazov IR, Kursky VF, Dykman LA, Nikitina VE. Biosynthesis of nanoparticles of metals and metalloids by basidiomycetes. Preparation of gold nanoparticles by using purified fungal phenol oxidases, Appl. Microbiol Biotechnol, 2016, 1-16. 